https://helda.helsinki.fi

The sustainability promise of alternative food networks: an pÿexamination through alternative characteristics

\title{
Forssell, Sini
}

2015

Forssell , S \& Lankoski , L 2015 , ' The sustainability promise of alternative food networks:

pÿan examination through alternative characteristics ', Agriculture and Human Values, vol. 32 , no. 1 , pp. 63-75 . https://doi.org/10.1007/s10460-014-9516-4

http://hdl.handle.net/10138/311159

https://doi.org/10.1007/s10460-014-9516-4

unspecified

acceptedVersion

Downloaded from Helda, University of Helsinki institutional repository.

This is an electronic reprint of the original article.

This reprint may differ from the original in pagination and typographic detail.

Please cite the original version. 


\title{
The sustainability promise of alternative food networks: an examination through "alternative" characteristics
}

\author{
Sini Forssell \\ Department of Economics and Management \\ University of Helsinki, Finland \\ P.O.Box 27, FI-00014 University of Helsinki, Finland \\ sini.forssell@helsinki.fi \\ Leena Lankoski \\ Department of Economics and Management \\ University of Helsinki, Finland \\ P.O.Box 27, FI-00014 University of Helsinki, Finland \\ $* * * * * * * *$
}

Published in Agriculture and Human Values (2015): 32(1), 63-75. The final publication is available at Springer via http://dx.doi.org/ 10.1007/s10460-014-9516-4

$* * * * * * * * *$

\begin{abstract}
Concerns about the unsustainability of the conventional food system have brought attention to so called alternative food networks (AFNs), which are widely thought to be more sustainable. However, claims made about AFNs' sustainability have been subject to a range of criticisms. Some of them present counterevidence, while others have pointed to problematic underlying features in the academic literature and popular discourse that may hamper our understanding of AFNs' sustainability.

Considering these criticisms, together with the fact that the literature often addresses a specific type of AFN or a specific sustainability-related issue, it is hard to form a clear overall picture of the sustainability promise of AFNs. In this article, we seek to contribute to a clearer understanding of this promise through a structured review, focusing on links between AFN characteristics and sustainability. Through an analysis of AFN conceptualizations reflected in the literature, we identify and consolidate their key characteristics. We then synthesize claims of how these characteristics may translate into sustainability, finding a wide range of potential direct and indirect impacts. Examining these from different angles, we find that the sustainability promise of AFNs found in these claims is qualified by the presence of potentially unaddressed issues, by criticisms regarding for example the evidence base of the assumed impacts and their power in addressing sustainability, and by considerations of how these impacts might play out in actual, real-life food networks. Indirect impacts of learning and participation may be highly significant for sustainability. We conclude with recommendations for research and practice.
\end{abstract}

Keywords Alternative food networks - Localized food systems - Short food supply chains • Sustainability 


\section{Introduction}

The current food system is coming under increasing criticism due to its negative sustainability impacts, both in terms of the environment and producers' and consumers' well-being (e.g., Kloppenburg et al. 1996; Anderson 2008). The growing interest in various "alternative" forms of food production and distribution is widely seen as a response to these concerns (e.g., Maye and Ilbery 2006; O'Hara and Stagl 2001; Selfa and Qazi 2005). Such "alternatives" are commonly called "alternative food networks" (AFN) (e.g., Renting et al. 2003; Jarosz 2008; Tregear 2011) and this is also used here as an umbrella term. AFNs are considered to include a variety of distribution and/or production practices, such as farmers' markets, Community Supported Agriculture and farm shops (e.g., Ilbery and Maye 2005a; Renting et al. 2003), consumer food co-operatives, specialist food retailers, organic agriculture, fair trade, and foods with a geographical indication of origin (e.g., Renting et al. 2003).

There is growing enthusiasm toward "relocalised" food networks and procuring foods through alternative channels among consumers (e.g., Thilmany et al. 2008; Zepeda 2009; Cone and Myhre 2000), activist organisations (e.g., Sustain 2013; Norberg-Hodge et al. 2002) and policy-makers (e.g., DEFRA 2002) alike in addressing the unsustainability of the current conventional food system. Tregear (2011) identifies "headline claims" also in academic literature about the beneficial nature of AFNs, including better livelihoods for farmers and economic benefits for local communities, healthier food for consumers, more ecological farming and reduced transport-related emissions. In some cases, she points out (p. 425), this is even reflected in conceptualizations expressing "the inherent characteristics of such systems in terms of their desired outcomes" (citing Whatmore et al. 2003 and Renting et al. 2003) or of AFNs as networks where the participants are committed to sustainability (citing Jarosz 2008).

Despite this general perception of AFNs being more sustainable, the assertions outlined above have been subject to criticisms, often looking at a specific type of food network and pointing to contradictory or problematic outcomes, or concentrating on a few specific sustainability-related issues in AFNs. Scholars have, for example, pointed out that AFNs do not necessarily have positive local economic impacts (Goodman 2004; Watts et al. 2005), that food in "re-localised" food systems or sold by direct sales is not necessarily sustainably farmed (Winter 2003; Watts et al. 2005), and that participants in AFNs such as farmers' markets or CSAs are not necessarily motivated by sustainability (e.g., Tregear 2011). Others have pointed out problematic underlying features in the literature. Holloway et al. (2007) refer to the danger of "romanticizing" the alternative, not subjecting it to the same critical reflection as conventional systems. Born and Purcell (2006) criticize the tendency to conflate the local scale of a food system with positive outcomes for the environment and local communities, while Tregear (2011, p. 425) expands on this, criticizing "the tendency to conflate the structural or spatial characteristics of AFNs with socially, economically and ecologically desirable outcomes". Such assumptions and conflations hamper our understanding about the sustainability of AFNs, with potential adverse consequences for efforts to build more sustainable food systems. Yet, despite the need for critical studies of the overall sustainability impacts of AFNs, there are to our knowledge only a few studies that have directly and explicitly addressed this, notably Ilbery and Maye (2005b) and Maxey $(2007,2006)$, who have conducted empirical studies of the sustainability of specific AFN types.

We wanted to address the question of AFNs' overall sustainability from a yet more high-level perspective, that is, encompassing the AFN phenomenon generally. To do this, we set out to examine the relationship of AFNs with sustainability through a conceptual analysis and structured review of the 
literature. Our research question is: What is it in these types of food provision that is seen to distinguish them from the conventional food system, and how do these features possibly translate into sustainability in food networks?

To lay the ground, we start with a brief discussion of the concept of sustainability in the context of food networks. We then turn to how AFNs have been described in the literature, and based on this, identify and consolidate the key characteristics that are seen to make AFNs "alternative". Next, we examine how the characteristics have been suggested to impact on sustainability. Through this analysis, we find a wide range of potential direct and indirect impacts. We then examine these from three different angles and find that the sustainability promise of AFNs is qualified by the presence of potentially unaddressed issues, criticisms regarding for example the evidence base of the assumed impacts and their power in addressing sustainability, and considerations of how these impacts might play out in real-life food networks. We also find that indirect impacts of learning and participation may be highly significant for sustainability. We end with a summary and conclusions, discussing the implications of our findings for building more sustainable food systems. The focus on characteristics allows us to present a clarified overview of AFNs' potential contribution to sustainability, drawing together what tends to be a dispersed and sometimes implicit theme in the literature.

\section{Sustainability in the food system}

The concept of sustainability has been the target of much defining and redefining (Robinson 2004). However, common to many attempts to define sustainability is that they "coalesce specifically around the concepts of carrying capacity, futurity, and environmental and socioeconomic long-term quality of life" (Starik and Kanashiro 2013, p. 12). Accordingly, sustainability is typically seen to encompass three dimensions: economic, social and environmental sustainability, which, crucially, must be balanced (e.g., Allen et al. 1991, cited in Hassanein 2003; Maxey 2006, 2007).

Beyond this broad view, what exactly constitutes sustainability, also in the food system, is much less clear (Hassanein 2003; Ilbery and Maye 2005b; Maxey 2007). The obstacles to reaching a definitive conceptualization are related to the difficulty of balancing often contradictory environmental, social and economic aspects (Hassanein 2003; Robinson 2004; Ilbery and Maye 2005b), the different interests of those involved (Redclift 2002) and the "considerable scientific uncertainty" in some realms (Hassanein 2003, p. 78). As sustainability is an indeterminate concept, ideas of what is sustainable are prone to being molded according to whichever interests are at play (Maxey 2007). This can be through, for example, privileging economic aspects over others (Robinson 2004), or privileging and presenting scientific knowledge as though it were unproblematic (Hassanein 2003; Redclift 2002). Maxey (2007, p. 58) argues that viewing sustainability as a "given entity which can be measured against a predetermined checklist" is, accordingly, problematic. Considering these concerns, many have argued for a more processual, inclusive and democratic approach to defining and addressing sustainability (Hassanein 2003; Robinson 2004; Kemp and Martens 2007; Maxey 2007), combining expert and lay understanding (Robinson 2004; Hassanein 2003).

Whilst mindful of the caution about fixed definitions, we do, however, need a background structure to the discussion about the sustainability impacts of AFNs in the literature. Thus, we outline here issues that are commonly considered central to sustainability in food networks. We draw on sources which represent academic, policy and non-governmental organization perspectives, and, given the focus of this paper, take a holistic food network sustainability perspective (Yakovleva 2007; Maloni and Brown 
2006; Forsman-Hugg et al. 2013; Sustainable Development Commission 2005; SUSTAIN 2002) and group the issues within the dimensions of environmental, economic and social sustainability.

Economic issues include the incomes and livelihoods of producers and others involved in the network, employment, and local economic development, particularly in rural areas. Social issues include labor rights and the safety of workers, consumer health, food culture, and the accessibility, availability and affordability of nutritious food (food security). Environmental impacts of food production, processing, packaging, distribution and consumption, in turn, have to do with the use of resources and with pollution and damage to the soil, water and air (including greenhouse gas emissions), biodiversity and ecosystems, and animal welfare. After identifying and consolidating key AFN characteristics below, we will reflect our synthesis of AFNs' suggested sustainability claims against this grouping of issues.

\section{Identifying and consolidating AFN characteristics}

To identify the characteristics that are seen to distinguish AFNs from the conventional food system, we draw from descriptions of alternative food networks in prominent contributions to the literature in Table 1. Considering AFN an umbrella term for several types of food production and distribution, we include descriptions that refer to the same wider phenomenon, even if they use slightly different terms.

Table 1 Descriptions of alternative food networks

\begin{tabular}{|c|c|}
\hline Author & Description \\
\hline $\begin{array}{l}\text { Marsden et } \\
\text { al. }(2000, \text { p. } \\
424-425)\end{array}$ & $\begin{array}{l}\text { "[...] resurgence of interest in 'more natural' or 'more local' foods [...] offers } \\
\text { potential for shifting the production of food commodities out of their 'industrial } \\
\text { mode' and to develop supply chains that can potentially 'short-circuit' the long, } \\
\text { complex and rationally organized industrial chains. [...] A key characteristic of short } \\
\text { supply chains is their capacity to re-socialize or re-spatialize food, thereby allowing } \\
\text { the consumer to make value-judgements about the relative desirability of foods } \\
{[\ldots] \text { 'Short' supply chains seek to redefine the producer-consumer relation by giving }} \\
\text { clear signals as to the origin of the food product. [...] A common characteristic, } \\
\text { however, is the emphasis upon the type of relationship between the producer and the } \\
\text { consumer in these supply chains, and the role of this relationship in constructing } \\
\text { value and meaning, rather than solely the type of product itself." }\end{array}$ \\
\hline $\begin{array}{l}\text { Whatmore et } \\
\text { al. (2003, p. } \\
389)\end{array}$ & $\begin{array}{l}\text { "[...] those diverse and dynamic food networks that had been cast as remnant or } \\
\text { marginal in the shadow of productivism [...] 'alternative' and/or 'quality' and/or } \\
\text { 'local' food networks (see Murdoch et al, 2000). These overlapping but nonidentical } \\
\text { collective nouns consolidate a multiplicity of food networks from organics and fair } \\
\text { trade to regional and artisanal products [...] What they share in common is their } \\
\text { constitution as/of food markets that redistribute value through the network against }\end{array}$ \\
\hline
\end{tabular}


the logic of bulk commodity production; that reconvene 'trust' between food producers and consumers; and that articulate new forms of political association and market governance."

Sage

(2003, p.

$47,49)$

Ilbery and

Maye

(2005a, p.

823-825)

"[...] there is also a growing appreciation of the socially embedded character of alternative food networks. [...] Recovering a sense of morality within the food and agriculture sector is arguably one of the important emerging characteristics of alternative food networks."

"Consumer interest in alternative foods has been accompanied by a growth in food sales from 'alternative' systems of food supply that are in some ways different from conventional chains (particularly supermarket outlets) [...] words such as 'quality', 'embedded', 'sustainable', 'traditional', 'natural', 'artisanal', and 'diversity' characterise alternative food production systems [...] Implicit in the notion of an alternative food supply system is the importance of key concepts such as localness, quality, trust and embeddedness."

Sonnino and

Marsden

(2006, p.

181)

Morgan et al.

(2006, p. 2)
"Variously and loosely defined in terms of 'quality', 'transparency', and 'locality', such newly emerging networks are (somewhat contentiously) signalling a shift away from the industrialized and conventional food sector, towards a re-localized food and farming regime. "

"[..] alternative [agri-food] system [...] which tends to be associated with a more ecological approach to agroculture, with smaller companies producing and retailing food for localized markets."

" [Researchers] conceptualize AFNs in relation to rural and regional development,

Jarosz

(2008, p.

232) various forms of capitalist restructuring, and as an ecological and social vision and discourse embracing environmental awareness and progressive social goals $[\ldots]$ AFNs are defined in four major ways: (1) by shorter distances between producers and consumers; (2) by small farm size and scale and organic or holistic farming methods, which are contrasted with large scale, industrial agribusiness; (3) by the existence of food purchasing venues such as food cooperatives, farmers' markets, and CSA and local food-to-school linkages; (4) by a commitment to [...] sustainable food production, distribution and consumption. “

An examination of the conceptualizations reflected in Table 1 shows that while a common underlying core is clearly perceptible, and the authors are not in contradiction with each other, the variation and great number of different characteristics used in attempts to capture the phenomenon of AFNs is notable. AFNs are characterized from the perspective of the foods that are circulating in the networks (e.g., natural, traditional, quality foods) and their production processes (e.g., ecological production), from the perspective of the networks used to arrange the supply of food (e.g., non-supermarket retail points, minimized number of intermediaries) and from the perspective of the participants in those networks (e.g., morality, social embeddedness). Implicit or explicit in all the descriptions in Table 1 is a comparison to "conventional" food networks.

Importantly, the characteristics that can be identified in the literature fall into three categories. One is the assumed values, goals and logics of AFN participants. However, as they do not directly result in changes to the provision of food, we consider these to be background characteristics, potentially driving participants to do things differently. Another category is what we call core characteristics, that is, those representing concrete changes to food provision, through types of products, production processes, distribution networks or forms of market governance involved. The third is outcome characteristics, expected results of operating food networks in an alternative way 
(social embeddedness, trust). Within these categories, we can consolidate AFN characteristics as follows:

1. Background characteristics

- $\quad$ Participants' non-conventional values and goals: morality, commitment to sustainability and the "non-industrial" logic driving how AFNs are operated.

2. Core characteristics

- Increased requirements for products and production. Products circulating in AFNs are often characterized as "natural", which we understand as unprocessed and/or without additives. Production in AFNs is characterized as environmentally benign, as using artisanal or traditional production methods, or as territorially embedded (foods being linked to a specific area and its traditions of production, Morgan et al. 2006) and by small scale and diversity. The notion of "quality" used in characterizing products and production in AFNs is also linked to these attributes.

- $\quad$ Reduced distance between producers and consumers, which relates to the network and distribution arrangements in AFNs. The characteristic of reduced distance links to notions of localness, small size of networks, transparency, information and "shortening" the supply chain. Here, we conceptualize reduced distance as encompassing three dimensions to capture its multiple meanings: physical distance, value chain distance (reflecting the number of intermediaries in the food supply chain) and informational distance (reflecting the ways in which AFNs increase the availability of information about foods, their production methods, producer and place of production, whether that be from face to face communication or through mechanisms such as labels or "value-laden" information on the packaging on products; see Marsden et al. 2000).

- New forms of market governance, or "new ways to coordinate production, purchasing and commercialization" (Taylor et al. 2005, p. 200). We understand these as being linked to AFNs such as Community Supported Agriculture, consumer or producer co-operatives and Fair Trade, and as such, containing the ideas of redistributing power in the food network and sharing economic risk and/or resources.

3. Outcome characteristics

- $\quad$ Strong relationships, exemplified by notions of trust and social embeddedness. These are a perceived outcome of particularly the reduced distance in AFNs.

It should be emphasized that real-life AFNs are highly variable in terms of which combinations of these characteristics they exhibit. It has also been debated whether certain characteristics are a sufficient marker of an AFN. For instance, while some consider organic production an AFN, this view has also been questioned (Watts et al. 2005, Ilbery and Maye 2005b). Watts et al. (2005, p. 34) distinguish between weaker and stronger AFNs based on whether the focus of an AFN is on the foods produced or the networks used to circulate these foods, thus, "their engagement with, and potential for subordination by, conventional [food supply chains]". In this paper, however, our purpose is not to determine what types of real-life food provision types qualify as AFNs, but to examine how the characteristics commonly attributed to AFNs may impact on sustainability.

\section{Suggested linkages between AFN characteristics and sustainability}

We now turn to examining how the key characteristics of alternative food networks have been argued to contribute to sustainability, based on prominent arguments presented in the literature about AFNs 
and/or food sustainability. The characteristic of participants' non-conventional values and goals is, as we have noted above, a background characteristic. It has been noted that AFN participants do not necessarily have these values and goals (Tregear 2011), and where they do, their presence alone does not directly contribute to sustainability. We do not intend here to downplay the role of these characteristics as they may be significant in what types of practices are adopted (Born and Purcell 2006), but sustainability outcomes are a result of those actual practices.

Reviewing the suggested sustainability impacts of other AFN characteristics, one can first of all differentiate between direct and indirect impacts. AFNs' core and outcome characteristics are linked directly to a number of specific sustainability impacts, but also to positive impacts that have a more indirect contribution to the specific aspects of sustainability identified above. These indirect impacts can be understood as feeding into and reinforcing participant values and the choices about preferred production methods, the form and length of food supply chains, and governance arrangements.

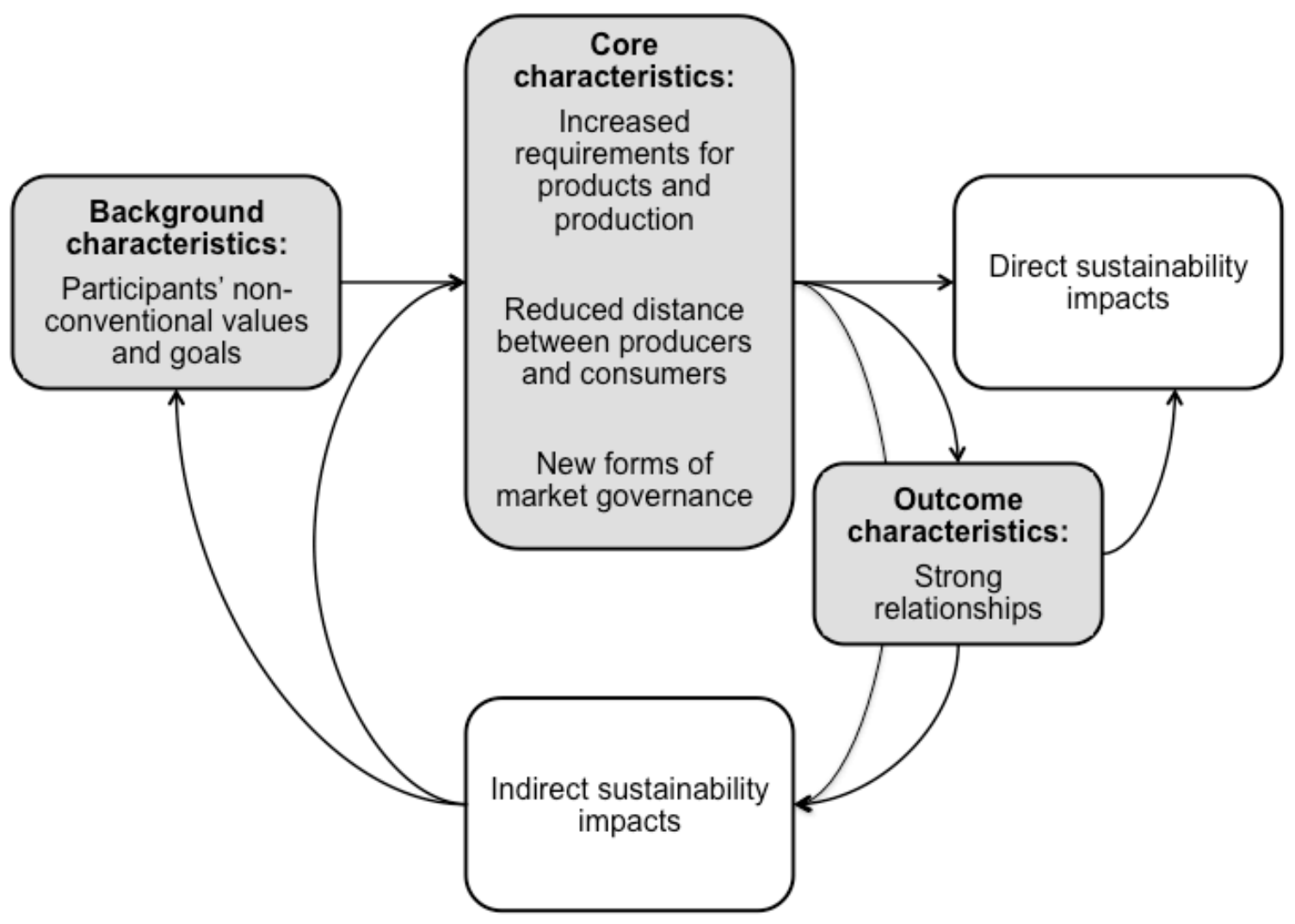

Fig. 1 Direct and indirect linkages between AFN characteristics and sustainability

The central direct sustainability impacts suggested in the literature are summarized in Table 2. First of all, in terms of environmental sustainability, the environmentally benign production choices (typically organic production) that are seen to characterize AFNs can have a positive impact across all aspects of environmental sustainability (see e.g., Gomiero et al. 2011 on organic production). The reduced physical distance in AFNs is thought to contribute to environmental sustainability through the reduction of the transportation distances of foods, or "food miles", equaling less fuel use and emissions to the air (e.g., Schonhart et al. 2009). 
In terms of economic sustainability, the production methods linked with AFNs as well as the characteristics of reduced distance, new forms of governance and strong relationships are believed to have positive impacts. AFNs are thought to contribute to producer livelihoods by adding value through differentiated production methods and reduced informational distance, where the value-laden information connected to a product may enable the producers to receive a higher price for it (Renting et al. 2003; Marsden et al. 2000). Schemes for territorially embedded production, such as geographical indications, can be a successful means of expanding markets beyond the region of production (Marsden et al. 2000) and offering sustained competitive advantage through creating regulatory market barriers (Goodman 2004). Social embeddedness is thought to bring producers the benefit of consumers accepting higher prices due to the nature of the exchange being based on other than narrow economic factors (Lee 2000). It is also argued that the reduced value chain distance in these networks, where there are little or no intermediaries, allows a greater share of that value to be captured by producers (e.g., Marsden et al. 2000) and indeed, bypassing middlemen and selling through direct markets may be the only way of getting access to markets for some small producers (Guthman et al. 2006). The redistribution of power and risk central to the new forms of governance in AFNs are also thought to contribute to producer livelihoods. Arrangements such as Community Supported Agriculture are built on the idea of sharing the economic risk in agriculture between producers and consumers through an advance payment system (e.g., Feagan and Henderson 2009), while the key ideas of another arrangement, producer co-operatives, include collectively having more negotiating power and resources, thus better market possibilities and income. Some of the production characteristics of AFNs may contribute to job creation, namely artisanal production (De Roest and Menghi 2000) and organic production (Lobley et al. 2009). Finally, thinking beyond individual producers or workers, the reduced physical distance in AFNs means money spent on food contributes to the local economy. The suggested social sustainability impacts in AFNs stem from the characteristics of products and production methods, from the reduced distance between producers and consumers and from strong relationships. Properties of food and its production and reduced physical distance are thought to contribute to consumer health. "Natural" foods (unprocessed, free of additives) are thought to be healthier than highly processed foods. The reduced physical distance in AFNs is believed by many activists and consumers to mean that food is fresher and retains more nutrients than food transported over long distances (Born and Purcell 2006). Environmentally benign production methods can also contribute to producer and consumer health and safety. Organic farming, for example, restricts the use of chemicals in plant production as well as hormones and antibiotics in animal rearing (European Commission 2007; Gold 2007), thus addressing product and producer safety and health impacts. Organic farming is linked to greater biodiversity, which in turn is considered critical for food security (Reisch et al. 2013) and thus access to food. Diversity of production may also mean genetic diversity of crops grown, also contributing to food security (Esquinas-Alcázar 2005). It is believed that reduced physical distance, through the preservation of local food production, contributes to food security (Schonhart et al. 2009) and that reduced value chain distance can also improve access to food from an affordability perspective as there are less intermediaries in the supply chain that would add to food costs (see Guthman et al. 2006). Finally, AFN characteristics are thought to have positive effects on food culture. The focus on territorial embeddedness and on traditional production methods is argued to contribute to the preservation of regional, traditional food cultures and diversity (Schonhart et al. 2009). Food culture can also be supported through people's increased visibility into and awareness of food provenance and production, which stems from the reduced informational distance in AFNs. While small scale farming may evoke images of farmers who have sustainability-related values, of 
equitable farm labor arrangements and of more careful tending of the earth, direct effects of small scale production are difficult to pinpoint. Some studies have found that small farms are more likely to have sustainable agricultural practices than large farms (Tavernier and Tolomeo 2004), while a review by James and Hendrickson (2010) finds mixed results in terms of effect of farm size on conservation and sustainable farming practices. In any case, these impacts arise from chosen production methods, not farm size in itself. Similarly, as Jarosz (2008) points out, aspects such as crop diversity (which links to food security) are not tied to farm size. The small size of farms may have its effects through other characteristics such as redistribution of power, through having more participants in production and controlling the land on which food is grown, rather than this power being concentrated in the hands of few (Berry 1987, cited by James and Hendrickson 2010). Often, small scale may simply be the result of other characteristics such as artisanal production or reduced physical distance and the impacts associated with small scale may in fact arise from these characteristics that typically co-occur with small scale.

(see Table 2 attached) 
Table 2 Suggested positive direct linkages between AFN characteristics and sustainability

\begin{tabular}{|c|c|c|c|c|}
\hline \multicolumn{2}{|c|}{ AFN characteristics } & \multirow[t]{2}{*}{ Environmental impacts } & \multirow[t]{2}{*}{ Economic impacts } & \multirow{2}{*}{$\begin{array}{l}\text { Social impacts } \\
\text { Less additives, nutrients intact }- \text { consumer health }\end{array}$} \\
\hline \multirow{5}{*}{$\begin{array}{l}\text { Requirements } \\
\text { for products } \\
\text { and } \\
\text { production }\end{array}$} & Natural foods & & & \\
\hline & $\begin{array}{l}\text { Environmentally } \\
\text { benign (organic) }\end{array}$ & $\begin{array}{l}\text { All aspects of environmental } \\
\text { sustainability, incl. animal welfare }\end{array}$ & $\begin{array}{l}\text { Adds value - producer livelihoods } \\
\text { Labor intensive - employment creation }\end{array}$ & $\begin{array}{l}\text { Reduced exposure to chemicals - producer } \\
\text { health and safety } \\
\text { Restriction of use of chemicals and hormones - } \\
\text { consumer health } \\
\text { Biodiversity - food security - access to food }\end{array}$ \\
\hline & Small scale & & & \\
\hline & $\begin{array}{l}\text { Artisanal, non- } \\
\text { industrial, diverse }\end{array}$ & & $\begin{array}{l}\text { Adds value - producer livelihoods } \\
\text { Labor intensive - employment creation }\end{array}$ & $\begin{array}{l}\text { Crop diversity - food security - access to food } \\
\text { Preserves traditional production methods - } \\
\text { preservation of food culture }\end{array}$ \\
\hline & Territorially embedded & & $\begin{array}{l}\text { Adds value - producer livelihoods } \\
\text { Expands markets - producer livelihoods }\end{array}$ & $\begin{array}{l}\text { Preserves regional production methods - } \\
\text { preservation of food culture }\end{array}$ \\
\hline \multirow[t]{3}{*}{$\begin{array}{l}\text { Reduced } \\
\text { distance }\end{array}$} & Physical distance & $\begin{array}{l}\text { Less "food miles" - reduced emissions } \\
\text { and fuel use }\end{array}$ & Supporting local economy & $\begin{array}{l}\text { Fresher food - consumer health } \\
\text { More local food production - strengthens food } \\
\text { security - access to food }\end{array}$ \\
\hline & Value chain distance & & $\begin{array}{l}\text { Producers capture greater share of value - } \\
\text { producer livelihoods }\end{array}$ & More affordable food - access to food \\
\hline & Informational distance & & Adds value - producer livelihoods & $\begin{array}{l}\text { Increases consumer awareness of food } \\
\text { production - preservation of food culture }\end{array}$ \\
\hline \multirow[t]{2}{*}{ Governance } & $\begin{array}{l}\text { Redistribution of } \\
\text { power }\end{array}$ & & Negotiation power - producer livelihoods & \\
\hline & $\begin{array}{l}\text { Sharing of risk and } \\
\text { resources }\end{array}$ & & $\begin{array}{l}\text { Reduces economic risk for producers - } \\
\text { producer livelihoods } \\
\text { Combining resources - better market } \\
\text { opportunities - producer livelihoods }\end{array}$ & \\
\hline $\begin{array}{l}\text { Strong } \\
\text { relationships }\end{array}$ & $\begin{array}{l}\text { Social embeddedness, } \\
\text { trust }\end{array}$ & & Adds value - producer livelihoods & \\
\hline
\end{tabular}


As illustrated in Fig.1, AFNs may also create indirect sustainability impacts related to learning and participation. Reduced informational distance is widely thought to increase participants' learning about and awareness of sustainability-related issues in the food system, whether through the face-to-face communication in farmers' markets (Milestad et al. 2010), being a CSA member (Cox et al. 2009, Feagan and Henderson 2009), or through labelingbased schemes such as organic production (Allen and Kovach 2000) or fair trade (Lyon 2006). This is seen in contrast with the conventional food system, in which the increasing distanciation of food production from its consumption reduces consumers' understanding and awareness about food production and "perpetuates the externalization of environmental and social costs" (Anderson 2008, p. 596). Social embeddedness is also thought to contribute to this aspect through creating a disincentive for producers to be dishonest about their production methods (Kirwan 2004). Increased learning and awareness in turn is thought to lead to more sustainable practices (Kloppenburg et al. 1996; Sundkvist et al. 2005). An even wider potential indirect sustainability impact is the so-called graduation effect (Cox et al. 2009), meaning the transfer of consumer sustainability awareness onto other areas than food consumption. AFNs are also thought to favor participation and engagement in food networks, through the more active role given to both producers and consumers particularly in those AFNs which embrace alternative forms of governance, for example Community Supported Agriculture (O’Hara and Stagl 2001; Lamine 2005).

\section{Discussion of the sustainability potential of AFNs}

Following the structured examination of the suggested sustainability linkages above, in this section we examine the potential of AFNs to contribute to sustainability from three different angles: What is the overall sustainability promise of AFNs? Are the suggested sustainability impacts likely to be realized in practice? How might real-life AFNs fulfill the sustainability promise?

Overall sustainability promise

Table 2 provides an overview of the potential direct linkages between AFN characteristics and sustainability. The great number of these potential linkages, covering all three dimensions of sustainability, indicate that the sustainability expectations placed on AFNs are not without grounds. A key observation however relates to sustainability aspects which are not linked to AFN characteristics. A notable example is the unclarity over whether labor rights are considered in AFNs (e.g., Allen et al. 2003; Brown and Getz 2008). Certain prominent strategies toward greater sustainability in the food system also remain outside the focus of the AFN phenomenon, for example reducing meat consumption or adopting a vegetarian diet (Morris and Kirwan 2006) and avoiding food waste. Thus, even if the positive sustainability impacts linked to AFNs sustainability were fully realized, not all food sustainability issues would be addressed.

The indirect impacts of learning and participation in food networks clearly link to the participatory notions of assessing and addressing sustainability, with potentially more informed, aware and empowered consumers and producers. These impacts can work to reverse the tendency of distanciation noted above and contribute to the maintenance of "local 
knowledge" valuable in addressing local context-specific issues (O'Hara and Stagl 2001). Thus, despite being "indirect" from the point of view of addressing specific sustainability issues, these impacts may be highly significant.

Finally, AFNs may have impacts on the wider food system by "sending a signal to other actors within the food system that may in turn influence their actions" (Kirwan 2004, p. 412) and showing that "conventional patterns in the agro-food system" are not the only possible ones (Shreck 2005, p. 22).

Debates related to individual impacts

While there is some empirical evidence supporting the potential sustainability impacts identified in Table 2, there are also a great number of studies, empirical and theoretical, suggesting that the impacts may not be so straightforward. Criticisms fall broadly into three groups: materialization or sufficiency of impacts, possible counter-effects and the relevance of impacts.

First, there are studies suggesting that certain impacts attributed to AFN characteristics may simply not materialize as thought, or be sufficient. Notably, some of this may stem from conflating one characteristic with another. This is illustrated by what Born and Purcell (2006) call "the local trap": automatically associating the local scale with for example sustainable production methods. Other criticisms relate to more particular shortcomings. For example, while governance arrangements such as Fair Trade have been found to contribute to higher incomes (Lyon 2006; Shreck 2005; Taylor et al. 2005), it has also been found that producer prices in fair trade may not be high enough (Lyon 2006). Even CSAs may not provide a living wage for farmers (Brown and Miller 2008) and the reduction of economic risk in CSAs may not materialize as it is unclear whether consumers are actually prepared to share the risk, i.e., stay on board after a poor harvest (Feagan and Henderson 2009; Hinrichs 2000). The realization of the suggested value adding effects to producers from social embeddedness is also not clear (Hinrichs 2000; Kirwan 2004), nor is the link between reduced value chain distance and affordable food (Guthman et al. 2006; Hinrichs 2000). In terms of indirect impacts, Tregear (2011) and Born and Purcell (2006) point out limitations to actually achieving a high-quality exchange of information (and thus learning effects) even if value chain distance is reduced to a face-to-face setting. The effects of participation (and democracy) in AFNs may not always live up to the theory. Fair trade has been criticized of top-down decision-making, not involving producers sufficiently (Shreck 2005; Lyon 2006; Taylor et al. 2005). Also CSAs, which in theory are inclusive and participatory, in fact often struggle with the lack of participation of consumer members (Cone and Myhre 2000; Pole and Gray 2013).

The sustainability impacts associated with AFN characteristics may also be accompanied by counter-effects. For example, organic production is generally found to have less adverse environmental impacts than conventional production in terms of, for example, soil health, biodiversity and emissions to water and air, as well as animal welfare (e.g. Gomiero et al. 2011). Organic production may, however, result in smaller yields and thus increase environmental impacts per product (ibid.). Reducing food miles may not bring net environmental benefits because the environmental impacts of food production differ in different locales with different growing conditions (Born and Purcell 2006; Edwards-Jones et 
al. 2008) and because small-scale local food distribution may be inefficient (Mariola 2008; Coley et al. 2009).

In the domain of economic sustainability, reduced value chain distance raises the question of when value is being redistributed, whom is it redistributed away from? Food circulating through several nodes would bring revenues to these nodes, which could also be for example small, local retailers. Also, while there is case study evidence supporting the prominent argument that reduced value chain distance results in producers capturing a greater share of the value (e.g. Kirwan 2004; Morris and Buller 2003), the net benefit to producers has been questioned by studies suggesting that direct selling to consumers may require significant resources, time and energy from the producers and its profitability in the end may not live up to the theory (Jarosz 2008; Ilbery and Maye 2005b; Milestad et al. 2010). Supporting local producers and businesses also includes the tradeoff of not supporting producers in other localities, with implications for development in those localities (Edwards-Jones et al. 2008). Differentiation as a rural development strategy is also risky as "producers of protected and speciality foods may end up competing against each other for finite niche markets" (Watts et al. 2005, p. 28).

As for social impacts, the codification linked to for instance geographic indication labels may promote standardization rather than protecting the diversity of traditional production and thus preservation of food culture (Bowen and De Master 2011). "Value added" products may benefit the producer, but be out of the reach of lower income consumers (Goodman 2004). Indeed, there seem to be tensions between the goals of producer livelihoods and access to affordable food (Guthman et al. 2006). While there may be a potential job creation effect in some production methods, the concerns about labor rights mentioned earlier need to be considered in this context.

Finally, certain sustainability impacts linked to AFNs have also been criticized on grounds of insufficient relevance. In the environmental domain, for example, reduced food miles may not be as significant as the mode of transport in reducing transport-related emissions (Coley, Howard and Winter 2011). Transportation also generally causes only a small part of the life-cycle greenhouse gas emissions of food (e.g., Weber and Matthews 2008; Virtanen et al. 2011). The claim that reduced physical distance would mean that food is fresher and more nutritious as it reaches the consumer has been challenged by considering the time, not just distance in transport, and factors such as availability of refrigeration equipment (Born and Purcell 2006) as more relevant factors. The claim about natural, unprocessed foods being healthier could be considered simplistic as the healthiness of a diet can only be considered as a whole (Edwards-Jones et al. 2008).

Real-life AFNs and sustainability

A final question to address is what part of the sustainability promise of AFNs may be realized by specific AFNs. The sustainability impacts are produced through AFN characteristics but real-life AFNs vary in their characteristics, and one might struggle to find an AFN that exhibits them all. For instance, farmers' markets are characterized by reduced distance in all its forms, and the sustainability potential related to these (with the limitations outlined above). Products sold at farmers' markets are typically, but not necessarily, produced in an environmentally friendly way and artisanally. As another example, fair trade has the 
characteristic of reduced informational distance and certain requirements for production, and most of all, reflects an altered form of governance. The practical sustainability potential is thus bounded in the first instance by which AFNs specifically we are talking about, and which characteristics those AFNs exhibit. Yet, conflations of different types of AFNs and their sustainability credentials can be identified in the literature as pointed out by Tregear (2011). Another consideration in real-life contexts is the relationship between alternative and conventional food networks. Much as alternative food networks tend to be conceptualized through separation from or resistance to conventional food networks, the boundary between the two is far from clear, and there have been many contributions to the literature that problematize this divide (e.g., Holloway et al. 2007; Sonnino and Marden 2006; Ilbery and Maye 2005a,b; Tregear 2011).

Within this "hybridity" discussion, one can distinguish two lines of argumentation, of which the first pays attention especially to the nodes present within the networks in question and their alternative or conventional nature. To give some examples, a producer's "upstream" sourcing may happen through a conventional chain (for example, a processor might source some ingredients from conventional suppliers) while "downstream" the food chain is separate from conventional chains (sold through alternative retail points) (Ilbery and Maye 2005a,b). Also, "alternative" foods can be and are sold through mainstream retailers (Marsden et al. 2000; Watts et al. 2005), sometimes to complement insufficient alternative distribution channels (Ilbery and Maye 2005b). Renting et al. (2003, p. 401) use Callon's (1986) concept of "obligatory passage points" to describe the role of "larger (conventional) market parties" in certain types of AFNs in providing the necessary economies of scale. Having access to the infrastructures of conventional networks can thus be advantageous, even necessary to performing AFNs. All in all, from this perspective, different networks can be seen to include "alternative" or "conventional" characteristics in different combinations, and "conventional" networks to exhibit some "alternative" characteristics, thus producing the related positive impacts.

The other strand within the hybridity discussion focuses on the logics involved: the primarily ethical or sustainability related logics linked to AFN actors and the industrial, profit-seeking logic linked to conventional actors. This divide has been debated, as AFN actors may exhibit “conventional" logics (Hinrichs 2000, Ilbery and Maye 2005b), and Tregear (2011) also notes that this focus might obscure "instances of altruism or justice" in conventional networks. This appears to further blur the alternative-conventional boundary.

The notion of logics is also used to explain why conventional networks' involvement in the AFN domain may be problematic. Common here are concerns that through the way they adopt "alternative" characteristics, corporate food system actors make it more difficult for smaller actors in the food system to compete in the market and/or limit or reduce the sustainability impacts linked to the characteristics in question. Notably, these concerns link to situations where AFNs create added economic value. The success of for example organic foods, fair trade and local foods attract actors who are considered to be driven by a profit logic (Jaffee and Howard 2010). This is perceived as problematic because of the economic threat to those thought to be supported in AFNs, both in terms of pushing down prices for products (Goodman 2004) and manipulating meanings or introducing rules that create barriers for smaller actors (Jaffee and Howard 2010; Sonnino and Marsden 2006; Guthman 2004). 
Scholars have also demonstrated the weakening of practices and even the standards governing them through the involvement of these actors. For example in organics, this has led to a focus on allowable inputs rather than more holistic farm management practices (Jaffee and Howard 2010; Guthman 2004; Allen and Kovach 2000), and in fair trade, on a set price rather than wider questions around trade relations (e.g, Jaffee and Howard 2010), thus removing or reducing some of the positive environmental and social impacts. Seen from this perspective, the background characteristics of participant's logics, values and goals may have an important role.

\section{Summary and conclusions}

Many hopes are being placed on AFNs in the quest towards more sustainable food systems. In this paper, we set out to directly explore the sustainability potential of AFNs. Through a structured review of the literature, we distilled key characteristics that capture the essence of AFNs, examined how these characteristics potentially link to various sustainability issues, and critically evaluated the sustainability promise that arose from these links and the boundaries of this promise.

To summarize our analysis, we found that AFN characteristics are potentially linked to several aspects of sustainability directly across all three domains of sustainability, as well as having indirect impacts, and thus AFNs may contribute to sustainability in many ways. Certain sustainability impacts are, however, absent from the linkages and thus there are sustainability issues that AFN characteristics in themselves do not address. Also, the suggested sustainability impacts linked to AFN characteristics clearly do not always materialize or have a sufficient positive impact, may be accompanied by counter-effects, or be of limited relevance. The promise of specific real-life AFNs is demarcated by what AFN characteristics they exhibit. Conventional food networks might also exhibit some AFN characteristics and have the related sustainability effects in those instances, but there are concerns about the way in which practices/characteristics are adopted. The indirect sustainability impacts of AFNs may be highly significant in addressing sustainability.

Directly linking the concept of AFNs to the concept of sustainability has not proven very fruitful in the past. Therefore, our approach was to break both concepts into components, to establish their linkages at that lower, component level, and then use these to examine the sustainability potential of AFNs. Viewing sustainability through the lens of AFN characteristics, we were able to contribute a clarified, unified overview that accommodates a broad body of literature, bringing together what was earlier a dispersed theme in the literature. We also distinguished between characteristics that can contribute directly and background characteristics that contribute through other characteristics, and between direct and indirect sustainability impacts, clarifying the mechanisms through which sustainability may be produced. Taking AFN characteristics as the starting point also helped to more satisfactorily address certain key complexities identified by Tregear (2011). One is the diversity of real life AFNs, with this approach helping to avoid the conflation of different types of AFNs and their potential sustainability impacts. The other is the elusive boundary between AFNs and conventional food networks, where this approach helps to see beyond a narrow focus on 
AFNs to assess which sustainability impacts can also be realized in food networks that may be considered conventional, thus moving in the direction of examining food networks on their own terms as advocated by Holloway et al. (2007).

Our findings have immediate implications for building more sustainable food systems and for future research. They suggest that while AFNs do offer real opportunities to promote sustainability directly, indirectly through enhanced learning and participation, and through potentially bringing sustainability considerations into the mainstream, the boundaries identified call for further consideration of several points. First, there is a need to introduce measures to promote the fulfillment of those aspects not directly addressed by AFN characteristics. This could for example be including considerations of labor rights in the rules or guidelines that exist in the AFN domain. Currently, organic standards (e.g., European Commission 2007) and rules for selling at farmers' markets (e.g., FARMA 2010) largely do not cover labor rights, nor do the rules of all Fair trade schemes (Terstappen et al. 2013). Also, aspects such as meat consumption and food waste merit further attention, and this is also consistent with the calls made for a more prominent consumption perspective in AFN studies (Holloway et al. 2007; Tregear 2011).

The debates about the realization of AFNs' sustainability promise also point to several necessary considerations. For one, it should be more carefully considered what evidence there actually is about the believed sustainability impacts, and in many cases there is a need for more empirical work. Potential counter-effects also need to be recognized and if they cannot be alleviated, there are consequent value judgments about what to prioritize. This reinforces the view that sustainability is not a matter of meeting fixed criteria (Maxey 2007), but a process of negotiation among potentially conflicting, shifting goals (Hassanein 2003). Finally, there is a need to consider the relevance of characteristics in promoting sustainability. For example, rather than focusing on scale of networks as such (localness, small scale) we would do best to focus on those characteristics that do have some material impacts (as also argued by Born and Purcell 2006) and consider which additional measures or characteristics would be relevant. This is exemplified by Coley, Howard and Winter's (2011) article on the questionable usefulness of food miles as a sustainability measure and the need to raise other aspects, such as methods of transport, to the fore.

In terms of real-life food networks, participants and policy-makers should be mindful of building and supporting such AFNs (or conventional food networks) that do exhibit characteristics linked to those sustainability issues that they wish to address. Considering the discussion about how conventional actors may appropriate and weaken practices, attention should be paid to how or to which extent the characteristics are adopted in these networks, and how to protect against the weakening of practices. The best ways of doing this are debated. Labeling and certification schemes are a common way, but this approach may be too costly for smaller producers and as the labeling processes themselves are prone to appropriation (e.g., Jaffee and Howard 2010), certification may ultimately be of limited effectiveness. Consumer awareness plays a significant role here too (ibid.), and the learning and participation potential of AFNs can promote awareness of for example the weakening of production standards.

All in all, if AFNs are to play a role in contributing to greater sustainability in the food system, we should have as correct a picture about that role as possible. In this paper we take 
some steps towards painting that picture.

\section{Acknowledgments}

We would like to thank the editor and the two anonymous reviewers for their insightful and constructive comments on this paper, as well as Anne Murcott who provided helpful commentary on an earlier version. Funding from the Finnish Cultural Foundation and the Foundation for Economic Education is gratefully acknowledged.

\section{References}

Allen, P., D. Van Dusen, J. Lundy, and S. Gliessman. 1991. Integrating social, environmental, and economic issues in sustainable agriculture. American Journal of Alternative Agriculture 6(1): 34-39.

Allen, P., and M. Kovach. 2000. The capitalist composition of organic: The potential of markets in fulfilling the promise of organic agriculture. Agriculture and Human Values 17(3): 221-232.

Allen, P., M. FitzSimmons, M. Goodman, and K. Warner. 2003. Shifting plates in the agrifood landscape: The tectonics of alternative agrifood initiatives in California. Journal of Rural Studies 19(1): 61-75.

Anderson, M.D. 2008. Rights-based food systems and the goals of food system reform. Agriculture and Human Values 25(4): 593-608.

Berry, W. 1987. A defense of the family farm. In Is there a moral obligation to save the family farm?, ed. G. Comstock, 347-360. Ames, Iowa: Iowa State University Press.

Born, B., and M. Purcell. 2006. Avoiding the local trap. Scale and food systems in planning research. Journal of Planning Education and Research 26(2): 195-207.

Bowen, S., and K. De Master. 2011. New rural livelihoods or museums of production? Quality food initiatives in practice. Journal of Rural Studies 21(1): 73-82.

Brown, S., and C. Getz. 2008. Towards domestic fair trade? Farm labor, food localism, and the 'family scale' farm. GeoJournal 73(1): 11-22.

Brown, C., and S. Miller. 2008. The impacts of local markets: A review of research on farmers markets and Community Supported Agriculture (CSA). American journal of agricultural economics 90(5): 1296 -1302.

Callon, M. 1986. Some elements of a sociology of translation: domestication of the scallops and fishermen of St. Brieuc Bay. In Power, action and belief. A new sociology of knowledge?, ed. J. Law, 196-233. London, UK: Routledge.

Coley, D., M. Howard, and M. Winter. 2011. Food miles: Time for a re-think? British Food Journal 113(7): 919 - 934.

Coley, D., M. Howard, and M.Winter. 2009. Local food, food miles and carbon emissions: A comparison of farm shop and mass distribution approaches. Food Policy 34(2): 150-155.

Cone, C.A., and A. Myhre. 2000. Community-Supported Agriculture: A sustainable alternative to industrial agriculture? Human Organisation 59(2): 187-197. 
Cox, R., L. Holloway, L. Venn, L. Dowler, J.R. Hein, M. Kneafsey, and H. Tuomainen. 2008. Common ground? Motivations for participation in a community-supported agriculture scheme. Local Environment 13(3): 203-218.

DEFRA (Department of Environment, Food and Rural Affairs). 2002. The Strategy for Sustainable Farming and Food. Facing the Future. DEFRA Publications.

http://archive.defra.gov.uk/foodfarm/policy/sustainfarmfood/documents/sffs.pdf. Accessed 23 March 2014

De Roest, K., and A. Menghi. 2000. Reconsidering 'traditional' food: The case of Parmigiano Reggiano cheese. Sociologia Ruralis 40(4): 439-451.

Edwards-Jones, G., L. Milà i Canals , N. Hounsome, M. Truninger, G. Koerber, B. Hounsome, P. Cross, E.H. York, A. Hospido, K. Plassman, I.M. Harris, R.T. Edwards, G.A.S. Day, A.D Tomos, S.J. Cowell, and D.L. Jones. 2008. Testing the assertion that 'local food is best': The challenges of an evidence-based approach. Trends in Food Science \& Technology 19(5): 265-274.

Esquinas-Alcázar, J. 2005. Protecting crop genetic diversity for food security: Political, ethical and technical challenges. Nature Reviews Genetics 6: 946-953

European Commission. 2007. Council Regulation (EC) No 834/2007 of 28 June 2007 on organic production and labelling of organic products and repealing Regulation (EEC) No 2092/91. http://eur-

lex.europa.eu/LexUriServ/LexUriServ.do?uri=OJ:L:2007:189:0001:0023:EN:PDF. Accessed 6 May 2014.

FARMA. 2010. Certification -abridged rules.

http://www.farmersmarkets.net/certification2.htm. Accessed 6 May 2014.

Feagan, R., and A. Henderson. 2009. Devon Acres CSA: Local struggles in a global food system. Agriculture and Human Values 26(3): 203-217.

Forsman-Hugg, S., J-M. Katajajuuri, I. Riipi, K. Järvelä, J. Mäkelä, and P. Timonen. 2013. Key CSR dimensions for the food chain. British Food Journal 115(1): 30-47.

Gold, M.V. 2007. What is organic production? United States Department of Agriculture National Agricultural Library. http://www.nal.usda.gov/afsic/pubs/ofp/ofp.shtml. Accessed 24 January 2013.

Gomiero, T., D. Pimentel, and M.G. Paoletti. 2011. Environmental impact of different agricultural management practices: Conventional vs. organic agriculture. Critical Reviews in Plant Sciences 30(1-2): 95-124.

Goodman, D. 2004. Rural Europe redux? Reflections on alternative agro-food networks and paradigm change. Sociologia Ruralis 44(1): 3-16.

Guthman, J., A.W. Morris, and P. Allen. 2006. Squaring farm security and food security in two types of alternative food institutions. Rural Sociology 71(4): 662-684.

Guthman, J. 2004. The trouble with 'organic lite' in California. A rejoinder to the conventionalization debate. Sociologia Ruralis 44(3):301-316.

Hassanein, N. 2003. Practicing food democracy: A pragmatic politics of transformation. Journal of Rural Studies 19(1): 77-86.

Hinrichs, C.C. 2000. Embeddedness and local food systems: notes on two types of direct agricultural market. Journal of Rural Studies 16(3): 295-303. 
Holloway, L., M. Kneafsey, L. Venn, R. Cox, E. Dowler, and H. Tuomainen. 2007. Possible food economies: A methodological framework for exploring food production-consumption relationships. Sociologia Ruralis 47(1): 1-19.

Ilbery, B., and D. Maye. 2005a. Alternative (shorter) food supply chains and specialist livestock products in the Scottish -English borders. Environment and Planning A 37(5): 823 844.

Ilbery, B., and D. Maye. 2005b. Food supply chains and sustainability: Evidence from specialist food producers in the Scottish/English borders. Land Use Policy 22(4): 331-344.

Jaffee, D., and P.H. Howard. 2010. Corporate co-optation of organic and fair trade standards. Agriculture and Human Values 27(4): 387-399.

Jarosz, L., 2008. The city in the country: Growing alternative food networks in Metropolitan areas. Journal of Rural Studies 24(3): 231-244.

James, H., and M.K. Hendrickson. 2010. Are farmers of the middle distinctively "good stewards"? Evidence from the Missouri Farm Poll, 2006. Journal of agricultural and environmental ethics 23(6): 571 -590

Kemp, R., and P. Martens. 2007. Sustainable development: How to manage something that is subjective and never can be achieved? Sustainability: Science, Practice, \& Policy 3(2): 5-14.

Kirwan, J. 2004. Alternative strategies in the UK agro-food system: Interrogating the alterity of farmers' markets. Sociologia Ruralis 44(4): 395-415.

Kloppenburg J., J. Hendrickson, and G.W. Stevenson. 1996. Coming in to the foodshed. Agriculture and human values 13(3): 33-42.

Lamine, C. 2005. Settling shared uncertainties: Local partnerships between producers and consumers. Sociologia Ruralis 45(5): 324-345.

Lee, R. 2000. Shelter from the storm? Geographies of regard in the worlds of horticultural consumption and production. Geoforum 31(2): 137-157.

Lobley, M., A. Butler, and M. Reed. 2009. The contribution of organic farming to rural development: An exploration of the socio-economic linkages of organic and non-organic farms in England. Land Use Policy 26(3): 723-735.

Lyon, S. 2006. Evaluating fair trade consumption: Politics, defetishization and producer participation. International Journal of Consumer Studies 30(5): 452-464.

Maloni, M.J., and M.E. Brown. 2006. Corporate social responsibility in the supply chain: An application in the food industry. Journal of Business Ethics 68(1): 35-52.

Mariola, M. 2008. The local industrial complex? Questioning the link between local foods and energy use. Agriculture and Human Values 25(2): 193-196.

Marsden, T., J. Banks, and G. Bristow. 2000. Food supply chain approaches: Exploring their role in rural development. Sociologia Ruralis 40(4): 424-438.

Maye, D., and B. Ilbery. 2006. Regional economies of local food production: Tracing food chain links between 'specialist' producers and intermediaries in the Scottish-English borders. European Urban and Regional Studies 13(4): 337-354.

Maxey, L. 2006. Can we sustain sustainable agriculture? Learning from small-scale Producersuppliers in Canada and the UK. The Geographical Journal 172(3): 230-244. 
Maxey, L. 2007. From 'alternative' to 'sustainable' food. 2007 In Alternative Food Geographies: Concepts and Debates, eds. D. Maye, L. Holloway, and M. Kneafsey, 55-75. Oxford, UK: Elsevier.

Milestad, R., L. Westberg, U. Geber, and J. Björklund. 2010. Enhancing adaptive capacity in food systems: Learning at farmers' markets in Sweden. Ecology and Society 15(3): 29.

Morgan, K., T. Marsden, and J. Murdoch. 2006. Worlds of Food: Place, Power and Provenance in the Food Chain. Oxford, UK: Oxford University Press.

Morris, C., and H. Buller. 2003. The local food sector: A preliminary assessment of its form and impact in Gloucestershire. British Food Journal 105(8): 559-566.

Morris, C., and J. Kirwan. 2006. Vegetarians: Uninvited, uncomfortable or special guests at the table of the alternative food economy? Sociologia Ruralis 46(3): 192-213.

Norberg-Hodge, H., T. Merrifield, and S. Gorelick. 2002. Bringing the Food Economy Home: Local Alternatives to Global Agribusiness. London, UK: Zed Books.

O'Hara, S.U. and S. Stagl. 2001. Global food markets and their local alternatives: A socioecological economic perspective. Population and Environment: A Journal of Interdisciplinary Studies 22(6): 533-554.

Pole, A., and M. Gray. 2013. Farming alone? What's up with the " $\mathrm{C}$ " in community supported agriculture. Agriculture and Human Values 30(1): 85-100.

Redclift, M. 2002. Pathways to Sustainability? Geography 87(3): 189-196.

Reisch, L., U. Eberle and S. Lorek. 2013. Sustainable food consumption: an overview of contemporary issues and policies. Sustainability: Science, Practice, \& Policy 9(2): 7-25.

Renard, M-C. 2005. Quality certification, regulation and power in fair trade. Journal of Rural Studies 21(4): 419-431.

Renting, H., T.K. Marsden, and J. Banks. 2003. Understanding alternative food networks: exploring the role of short food supply chains in rural development. Environment and Planning A 35(3): 393-411.

Robinson, J. 2004. Squaring the circle? Some thoughts on the idea of sustainable development. Ecological Economics 48(4): 369-384.

Sage, C. 2003. Social embeddedness and relations of regard: alternative 'good food' networks in south-west Ireland. Journal of Rural Studies 19(1): 47-60.

Schonhart, M., M. Penker, and E. Schmid. 2009. Sustainable local food production and consumption. Challenges for implementation and research. Outlook on Agriculture 38(2): $175-182$.

Selfa, T., and J. Qazi. 2005. Place, taste, or face-to-face? Understanding producer-consumer networks in "local" food systems in Washington State. Agriculture and Human Values 22(4): 451-464.

Shreck, A. 2005. Resistance, redistribution and power in the Fair Trade banana initiative. Agriculture and Human Values 22(1): 17-29.

Sonnino, R. and T. Marsden. 2006. Beyond the divide: rethinking relationships between alternative and conventional food networks in Europe. Journal of Economic Geography 6(2): 181-199. 
Starik, M. \& Kanashiro, P. 2013. Toward a theory of sustainability management: uncovering and integrating the nearly obvious. Organization \& Environment 26(1): 7-30.

Sundkvist, Å., Milestad, R., and A. Jansson. 2005. On the importance of tightening feedback loops for sustainable development of food systems. Food Policy 30(2): 224-239.

Sustain. 2013. The Sustain Guide to Good Food. Sustain: The alliance for better food and farming, London.

Sustain. 2002. Sustainable food chains. Briefing paper 1. Local food; benefits, obstacles and opportunities. Sustain: The alliance for better food and farming, London.

http://www.sustainweb.org/pdf/briefing1.pdf. Accessed 28 March 2014

Sustainable Development Commission. 2005. Sustainability implications for the Little Red Tractor Scheme. http://www.sd-commission.org.uk/publications.php?id=195. Accessed 28 March 2014.

Tavernier, E.M., and V. Tolomeo. 2004. Farm typology and sustainable agriculture: does size matter? Journal of sustainable agriculture 24(2): 33-46.

Taylor, P.L., D.L. Murray, and L.T. Raynolds. 2005. Keeping trade fair: governance challenges in the fair trade coffee initiative. Sustainable Development 13(3): 199-208.

Terstappen, V., L. Hanson, and D. McLaughlin. 2013. Gender, health, labor, and inequities: a review of the fair and alternative trade literature. Agriculture and Human Values 30(1): 21-39.

Thilmany, D., C.A. Bond, and J.K. Bond. 2008. Going local: exploring consumer behaviour and motivations for direct food purchases. American Journal of Agricultural Economics 90(5): 1303-1309.

Tregear, A. 2011. Progressing knowledge in alternative and local food networks: Critical reflections and a research agenda. Journal of Rural Studies 27(4): 419-430.

Virtanen, Y., S. Kurppa, M. Saarinen, J-M. Katajajuuri, K. Usva, I. Mäenpää, J. Mäkelä, J. Grönroos, and A. Nissinen. Carbon footprint of food - approaches from national input-output statistics and a LCA of a food portion. Journal of Cleaner Production 19(16): 1849-1856.

Watts, D.C.H., B. Ilbery, and D. Maye. 2005. Making reconnections in agro-food geography: alternative systems of food provision. Progress in Human Geography 29(1): 22-40.

Weber, C.L., and H.S. Matthews. 2008. Food-miles and the relative climate impacts of food choices in the United States. Environmental Science \& Technology 42(10): 3508-3513.

Whatmore, S., P. Stassart, and H. Renting. 2003. What's alternative about alternative food networks? Environment and Planning A 35: 389-391.

Winter, M. 2003. Embeddedness, the new food economy and defensive localism. Journal of Rural Studies 19(1): 23-32.

Yakovleva, N. 2007. Measuring the sustainability of the food supply chain: A case study of the UK. Journal of Environmental Policy \& Planning 9(1): 75-100.

Zepeda, L. 2009. Which little piggy goes to market? International Journal of Consumer Studies 33(3): 250-257. 